\title{
əToward a Consistent Definition between Satellite and Model Clear-Sky Radiative Fluxes
}

\author{
Norman G. Loeb, ${ }^{a}$ Fred G. Rose, ${ }^{\mathrm{b}}$ Seiji Kato, ${ }^{\mathrm{a}}$ David A. Rutan, ${ }^{\mathrm{b}}$ Wenying Su, ${ }^{\mathrm{a}}$ Hailan Wang, ${ }^{\mathrm{b}}$ \\ DAVID R. DOELLING, ${ }^{a}$ WILliAM L. SMITH, ${ }^{a}$ AND ANDREW GETTELMAN ${ }^{\mathrm{c}}$ \\ ${ }^{\mathrm{a}}$ NASA Langley Research Center, Hampton, Virginia \\ ${ }^{\mathrm{b}}$ Science Systems and Applications, Inc., Hampton, Virginia \\ ${ }^{\mathrm{c}}$ National Center for Atmospheric Research, Boulder, Colorado
}

(Manuscript received 28 May 2019, in final form 13 August 2019)

\begin{abstract}
A new method of determining clear-sky radiative fluxes from satellite observations for climate model evaluation is presented. The method consists of applying adjustment factors to existing satellite clear-sky broadband radiative fluxes that make the observed and simulated clear-sky flux definitions more consistent. The adjustment factors are determined from the difference between observation-based radiative transfer model calculations of monthly mean clear-sky fluxes obtained by ignoring clouds in the atmospheric column and by weighting hourly mean clear-sky fluxes with imager-based clear-area fractions. The global mean longwave ( $\mathrm{LW}$ ) adjustment factor is $-2.2 \mathrm{~W} \mathrm{~m}^{-2}$ at the top of the atmosphere and $2.7 \mathrm{~W} \mathrm{~m}^{-2}$ at the surface. The LW adjustment factors are pronounced at high latitudes during winter and in regions with high uppertropospheric humidity and cirrus cloud cover, such as over the west tropical Pacific, and the South Pacific and intertropical convergence zones. In the shortwave (SW), global mean adjustment is $0.5 \mathrm{~W} \mathrm{~m}^{-2}$ at TOA and $-1.9 \mathrm{~W} \mathrm{~m}^{-2}$ at the surface. It is most pronounced over sea ice off of Antarctica and over heavy aerosol regions, such as eastern China. However, interannual variations in the regional SW and LW adjustment factors are small compared to those in cloud radiative effect. After applying the LW adjustment factors, differences in zonal mean cloud radiative effect between observations and climate models decrease markedly between $60^{\circ} \mathrm{S}$ and $60^{\circ} \mathrm{N}$ and poleward of $65^{\circ} \mathrm{N}$. The largest regional improvements occur over the west tropical Pacific and Indian Oceans. In contrast, the impact of the SW adjustment factors is much smaller.
\end{abstract}

\section{Introduction}

Cloud radiative effect (CRE), defined as the difference between the radiative flux over a region in the presence of clouds and that under cloud-free conditions, is one of the highest priority quantities used in climate model evaluation efforts (Burrows et al. 2018). Its use in climate model evaluation was first proposed in Ramanathan (1987) and Cess and Potter (1987), and first demonstrated in Ramanathan et al. (1989). Since then, many studies have used satellite observations from the Earth's Radiation Budget Experiment (ERBE; Barkstrom 1984) and the Clouds and the Earth's Radiant

Denotes content that is immediately available upon publication as open access.

Corresponding author: Dr. Norman G. Loeb, norman.g.loeb@ nasa.gov
Energy System (CERES; Wielicki et al. 1996) to assess model representation of CRE.

A necessary step in calculating CREs from observations and models is the determination of clear-sky fluxes. Cess et al. (1992) and Potter et al. (1992) recognized early on that the methodologies used to determine clearsky flux from satellite observations and models differ, resulting in systematic biases unrelated to model error (Sohn et al. 2006; Kato et al. 2013). Table 1 summarizes the methodologies used to determine clear-sky flux in observations and models. Method 1 refers to clear-sky fluxes from regions within a grid box that are cloud free as determined using satellite remote sensing. In CERES, cloud-free footprints are identified using high spatial resolution spectral imager pixel data (Trepte et al. 2019). The CERES Energy Balanced and Filled (EBAF) processing enhances the clear-sky sampling by also inferring clear-sky fluxes from the clear portions of CERES footprints with a cloud fraction of up to $95 \%$ (Loeb et al. 2018). Method 2 is a model or calculated clear-sky flux 
TABLE 1. Clear-sky flux definitions in models and observations. Symbols describe the flux ("F") for clear skies ("cs") derived from CERES observations (" $O$ "), climate models (" $M$ "), and radiative transfer model calculations initialized with observations (" $C$ ").

\begin{tabular}{|c|c|c|c|}
\hline Historical name & Source & Description & Symbol \\
\hline Method 1 (Potter et al. 1992) & Observation & $\begin{array}{l}\text { Observed clear-sky flux for cloud-free regions within grid } \\
\text { box }\end{array}$ & $F_{\mathrm{cs}}^{O}$ \\
\hline Method 1b (Potter et al. 1992) & Model & $\begin{array}{l}\text { Model clear-sky flux over grid box weighted by model clear- } \\
\text { sky fraction }\end{array}$ & $F_{\mathrm{cs}}^{M}(\mathrm{ModWgt})$ \\
\hline Method 1c & Hybrid & $\begin{array}{l}\text { Calculated clear-sky flux over grid box weighted by } \\
\text { observed clear-sky fraction }\end{array}$ & $F_{\mathrm{cs}}^{C}(\mathrm{ObsWgt})$ \\
\hline Method 2 & Model & $\begin{array}{l}\text { Model or calculated clear-sky flux over grid box determined } \\
\text { by ignoring clouds in the atmospheric column }\end{array}$ & $\begin{array}{l}F_{\mathrm{cs}}^{M}(\text { CldRem }) \\
F_{\mathrm{cs}}^{C}(\text { CldRem })\end{array}$ \\
\hline
\end{tabular}

over a grid box determined by ignoring clouds in the atmospheric column. It is commonly computed immediately following an all-sky radiative transfer calculation that includes clouds and therefore uses identical properties as the all-sky calculation (e.g., surface temperature, temperature/humidity profile, surface albedo, aerosol), but with clouds removed. As such, Method 2 includes contributions from atmospheric columns that are moister than Method 1. According to Sohn et al. (2006), this difference in atmospheric moisture explains why Method 2 clear-sky longwave (LW) fluxes at the top-of-atmosphere (TOA) are systematically lower than observations (Method 1), with differences reaching $12 \mathrm{~W} \mathrm{~m}^{-2}$ in convectively active regions.

Method $1 \mathrm{~b}$ is a model approach that attempts to mimic the observed clear-sky flux. It uses model-derived clear-sky fractions to weight Method 2 clear-sky fluxes. Less weight is assigned to the moister atmospheric columns since they are more likely to be cloudy than drier columns, resulting in a larger clear-sky LW TOA flux. In principle, the sampling strategy in this approach is closer to that for EBAF clear-sky observed fluxes than Method 2, but the disadvantage is that clear-sky flux errors associated with errors in the model clear-sky fraction weights cannot be separated from errors in the intrinsic flux calculation in a cloud-free column. Further complicating matters is that different climate models use different cloud parameterization schemes, which may require different approximations and implementations. As a result, most modeling groups tend to compare CERES EBAF clear-sky TOA fluxes and CREs with Method 2-based clear-sky model values.

In this study, we present a new approach that enables "apples to apples" comparisons between CERES and climate model (Method 2 based) clear-sky fluxes and CREs. The approach involves adding adjustment factors to observed CERES EBAF clear-sky fluxes in order to provide fluxes defined more consistently with climate models. The adjustment factors are given by the difference between calculated TOA fluxes determined using Methods 2 and 1 clear-sky sampling approaches. The
Method 2 calculations are taken directly from the CERES SYN1deg product (Rutan et al. 2015; Kato et al. 2018) and consist of radiative transfer model calculations initialized with observations. Similar to Method 1b, we also calculate Method 2 clear-sky fluxes weighted by clear-sky fractions, but we use observed imager-derived clear-sky fraction weights instead of model-derived values (Method 1c in Table 1).

In the following section we describe the methodology and data used to determine the LW and SW adjustment factors. Section 3 shows the magnitude of the adjustment factors at regional, zonal and global scales and compares them with those determined using other reanalyses. We also show the impact of the adjustment factors on the annual cycle of and interannual variations in CRE, and compare zonal and regional mean CREs with those from climate models. Section 4 provides a discussion of uncertainties in TOA and surface all-sky, clear-sky and CRE fluxes after accounting for all known error sources. Section 5 summarizes the main findings.

\section{Data and methods}

We derive a regional monthly adjustment factor $\left(\Delta^{C}\right)$ to the EBAF observed regional monthly mean clear-sky flux $\left(F_{\mathrm{cs}}^{O}\right)$ that enables direct comparisons with model clear-sky fluxes determined using Method 2 as follows:

$$
\begin{aligned}
F_{\mathrm{cs}}^{o}(\text { CldRem }) & =F_{\mathrm{cs}}^{o}+\Delta^{C}, \text { where } \\
\Delta^{C} & =F_{\mathrm{cs}}^{C}(\text { CldRem })-F_{\mathrm{cs}}^{c}(\mathrm{ObsWgt}) .
\end{aligned}
$$

$F_{\text {cs }}^{C}($ CldRem $)$ corresponds to radiative transfer model flux calculations over a grid box determined by ignoring clouds in the atmospheric column (Method 2). The flux calculations are initialized using satellite-derived cloud and aerosol properties, and temperature and specific humidity profiles from reanalysis. $F_{\mathrm{cs}}^{C}(\mathrm{CldRem})$ calculations are made hourly and averaged monthly, and are a standard output of the CERES SYN1deg Ed4.0 data product (Rutan et al. 2015; Kato et al. 2018). In CERES 
SYN1deg Ed4.0, temperature, specific humidity, and ozone profiles are from the NASA Goddard Earth Observing System, version 5.4.1 (GEOS-5.4.1), reanalysis (Rienecker et al. 2008). Aerosol data are based upon the Model of Atmospheric Transport and Chemistry (MATCH; Collins et al. 2001), which assimilates Moderate Resolution Imaging Spectroradiometer (MODIS) aerosol optical depth and provides hourly aerosol optical depths and aerosol type. Surface albedo and emissivity input data used in the radiative transfer model calculations are described in detail in Rutan et al. (2015).

$F_{\text {cs }}^{C}(\mathrm{ObsWgt})$ is the calculated clear-sky flux over a grid box weighted by observed clear-sky fraction (Method 1c in Table 1). It is derived from hourly $F_{\text {cs }}^{C}($ CldRem) in SYN1deg Ed4.0 weighted by MODIS clear-sky fraction weights. The clear-sky fraction weights are derived by sorting instantaneous CERES footprint clear-sky fractions from the CERES Single Scanner Footprint (SSF) TOA/Surface Fluxes and Clouds Ed4.0 product into $1^{\circ} \times 1^{\circ}$ regions. Clear-sky fractions within CERES footprints are determined by applying a cloud mask to each MODIS pixel and classifying it as clear or cloudy (Trepte et al. 2019). To produce hourly clear-sky fraction weights, the clear-sky fractions are temporally interpolated for Terra-only observation times prior to July 2002 and both Terra and Aqua observation times from July 2002 onward. The monthly mean $F_{\mathrm{cs}}^{C}(\mathrm{ObsWgt})$ is determined by first calculating monthly hourly averages and then averaging the monthly hourly means. In the $\mathrm{SW}, F_{\mathrm{cs}}^{C}(\mathrm{ObsWgt})$ is normalized by the ratio of the TOA insolation for complete temporal sampling over a month to that corresponding to clear-sky weighted temporal sampling. This ensures that $\Delta^{C}$ is not impacted by a diurnal cycle sampling bias due to the clear-sky weighting.

Because the early part of the record relies on Terra only (March 2000-June 2002) and the remainder uses both Terra and Aqua, an adjustment is applied to the Terra-only part of the record in order to minimize any discontinuities between these two periods. A discontinuity can arise because observations during the Terraonly period are only available twice daily compared to four times daily during the combined Terra-Aqua period and because of differences in the character of the cloud masks applied to Terra and Aqua MODIS data. Both can cause differences in clear-sky sampling and introduce a discontinuity. To mitigate this, we apply adjustments to the Terra-only part of the record determined from the difference between climatological monthly mean values of $F_{\mathrm{cs}}^{C}(\mathrm{ObsWgt})$ for Terra and Aqua combined and Terra only. We use a 10-yr period between July 2005 and June 2015 to derive the adjustments for each calendar month.
The above procedure is essentially the same at TOA and at the surface. In both cases, the adjustment factors are applied to EBAF TOA and surface Ed4.0 clear-sky fluxes described in Loeb et al. (2018) and Kato et al. (2018), respectively. In this study, we consider the EBAF Ed4.0 TOA and surface data for the Terra-Aqua period between July 2002 and September 2018.

\section{Results}

\section{a. Regional, zonal, and global mean $\Delta^{C}$ climatology}

The regional distribution of $\Delta^{C}$ for seasonal months averaged over 10 years (July 2005-June 2015) is shown in Figs. 1a-d for TOA LW and Figs. 2a-d for TOA SW. The corresponding Hovmöller diagrams of the annual cycle of zonal mean $\Delta^{C}$ are shown in Figs. $3 \mathrm{a}$ and $3 \mathrm{~b}$. In the LW, the $\Delta^{C}$ adjustment is generally negative throughout the year in the tropics and midlatitudes and is positive at high latitudes during winter, spring, and fall, and near zero during summer. The most pronounced values occur during January over Australia, reaching $-12 \mathrm{~W} \mathrm{~m}^{-2}$, and over Greenland, reaching $18 \mathrm{Wm}^{-2}$ (Fig. 1a). The larger LW $\Delta^{C}$ adjustments over parts of Greenland occur because skin temperatures over higher-elevation regions are highly sensitive to cloud cover. When present, clouds offset surface LW radiative cooling, keeping surface temperatures warm compared to cloud-free conditions. The overall global mean LW $\Delta^{C}$ for the entire July 2005-June 2015 period is $-2.2 \mathrm{Wm}^{-2}$ and the standard deviation is $0.15 \mathrm{Wm}^{-2}$ based upon the 120 monthly mean global values.

In the tropics the spatial pattern of $\Delta^{C}$ is closely tied to the pattern of upper-tropospheric humidity and cirrus. Regions with elevated upper-tropospheric humidity and cirrus lower the monthly mean LW $F_{\text {cs }}^{C}(\mathrm{CldRem})$ compared to $F_{\text {cs }}^{C}(\mathrm{ObsWgt})$, which favors drier and less cloudy conditions. The $\Delta^{C}$ adjustments are pronounced in the west tropical Pacific, South Pacific convergence zone (SPCZ), and intertropical convergence zone (ITCZ) and are closer to zero over the stratocumulus regions off the west coasts of North and South America, Africa, and Australia. The $\Delta^{C}$ adjustment at high latitudes is positive most of the time because in the presence of cloud, surface and boundary layer temperatures tend to be warmer than cloud-free conditions, resulting in larger LW fluxes for $F_{\text {cs }}^{C}(\mathrm{CldRem})$ compared to $F_{\mathrm{cs}}^{C}(\mathrm{ObsWgt})$. This effect is particularly strong over Greenland during January.

In the SW, $\Delta^{C}$ remains near zero over large portions of the ice-free oceans, and ranges between 1 and $3 \mathrm{~W} \mathrm{~m}^{-2}$ over the North Pacific and North Atlantic Oceans during April and July (Figs. 2b,c) as well as parts of the Southern Ocean in January and October (Figs. 2a,d). The $\Delta^{C}$ values reach $5 \mathrm{~W} \mathrm{~m}^{-2}$ during July over the Bay of Bengal during the Indian monsoon as well as over the 
(a) January

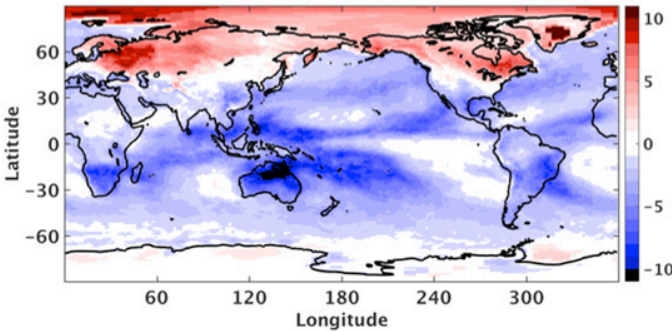

(c) July

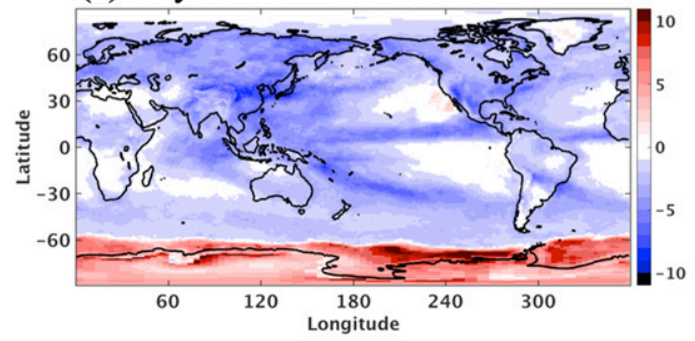

(b) April

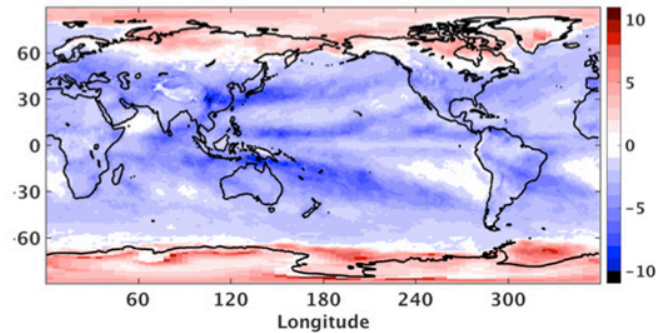

(d) October

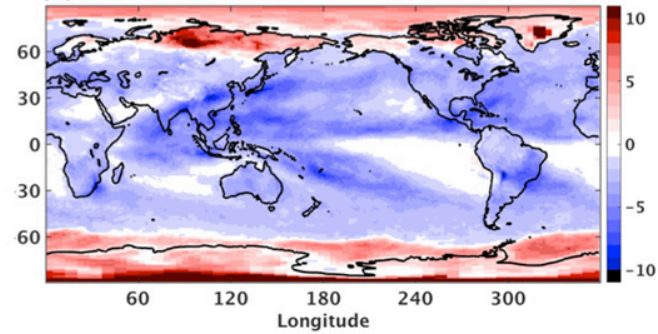

FIG. 1. TOA LW adjustment $\left(\Delta^{C}\right)$ for (a) January, (b) April, (c) July, and (d) October based upon 10-yr climatology of CERES EBAF data for July 2005-June 2015 (units: $\mathrm{W} \mathrm{m}^{-2}$ ).

northern part of the Arabian Sea (Fig. 2c). Over land, $\Delta^{C}$ is large over eastern China all year round, reaching $12 \mathrm{~W} \mathrm{~m}^{-2}$ in April. Appreciable negative values of $\Delta^{C}$ occur over parts of northern Russia and eastern Canada during April. When averaged globally, the overall mean SW $\Delta^{C}$ for the entire July 2005-June 2015 period is $0.47 \mathrm{~W} \mathrm{~m}^{-2}$ and the standard deviation is $0.16 \mathrm{~W} \mathrm{~m}^{-2}$ based upon the 120 monthly mean global values.

Over snow-free land surfaces, the SW $\Delta^{C}$ adjustment tends to be positive because the cloudier days tend to

(a) January

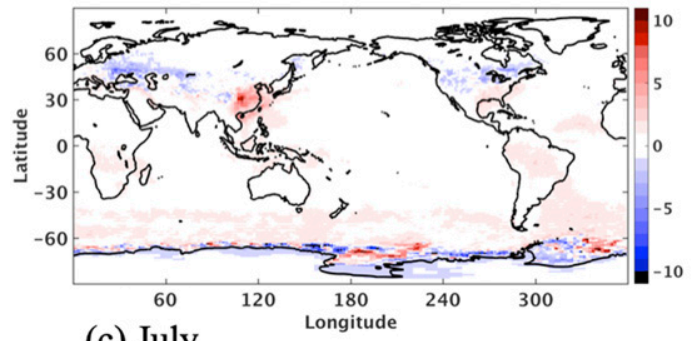

(c) July

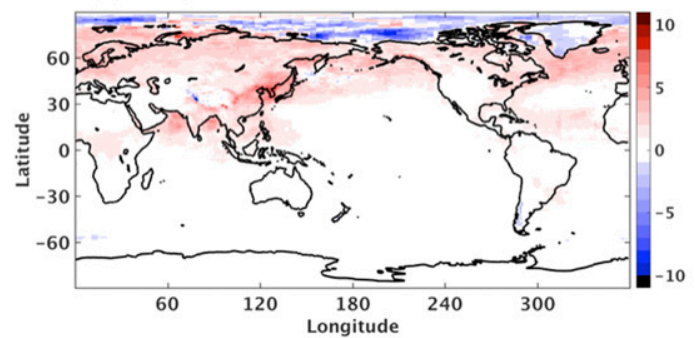

have larger aerosol optical depths, resulting in larger $F_{\text {cs }}^{C}($ CldRem) monthly mean values. The larger aerosol optical depths on cloudier days could be due to higher aerosol loadings and also because aerosol optical depth increases with relative humidity (Clarke et al. 2002). Another contributing factor could be from biases in the MODIS clear-sky weights. During days with heavy aerosol loadings over land, discriminating between clear and cloudy imager pixels is extremely challenging. If there is a tendency to misidentify heavy aerosol as cloud,

\section{(b) April}

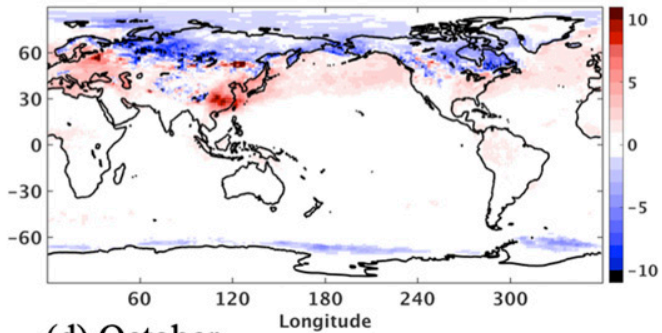

(d) October

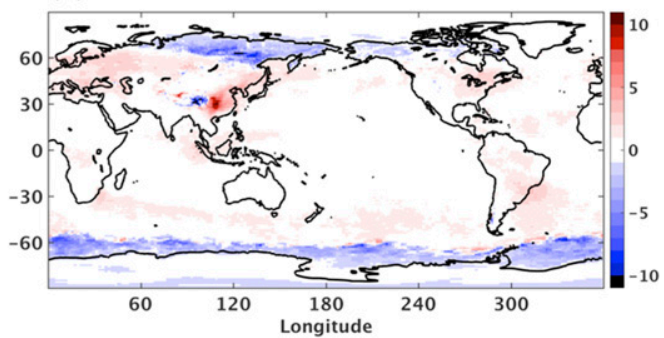

FIG. 2. As in Fig. 1, but for TOA SW $\Delta^{C}$ (units: $\mathrm{W} \mathrm{m}^{-2}$ ). 
(a) LW

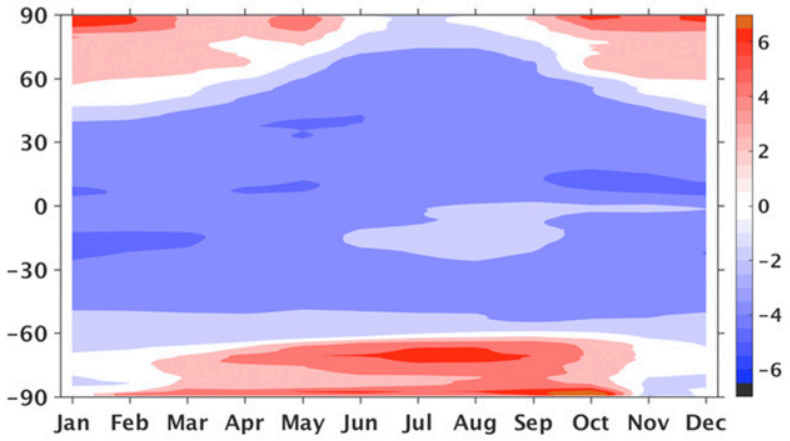

(b) SW

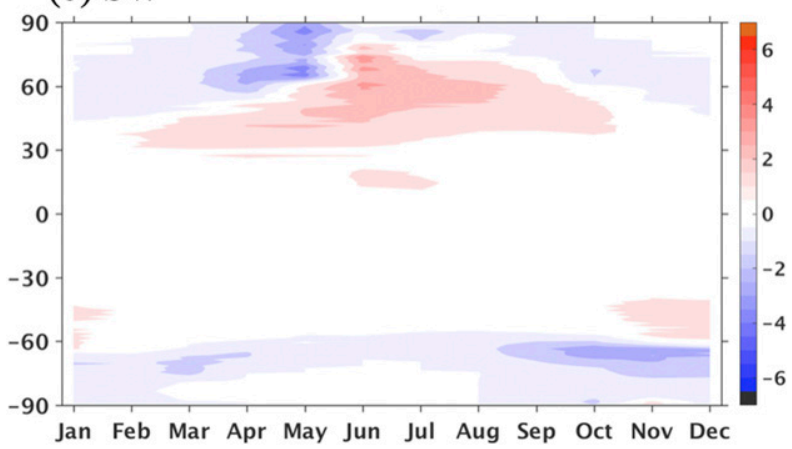

FIG. 3. Hovmöller plots of climatological monthly zonal mean $\Delta^{C}$ for (a) LW and (b) SW (units: $\mathrm{W} \mathrm{m}^{-2}$ ).

this will bias the $F_{\mathrm{cs}}^{C}(\mathrm{ObsWgt})$ value low, resulting in a positive SW $\Delta^{C}$ adjustment. Over Northern Hemisphere land regions with seasonal snow cover (e.g., in April), we suspect there may be a correlation between snow and cloud cover. For example, if the cloud cover is lower when the surface is covered with snow, the clear-sky weighting will assign more weight to the days of the month when the surface is snow covered, leading to a larger monthly mean for $F_{\mathrm{cs}}^{C}(\mathrm{ObsWgt})$ and a negative SW $\Delta^{C}$ adjustment. The reason for a correlation between snow and cloud cover may be physical or it could also result from inconsistent cloud identification between snow and snow-free covered days. If the cloud mask algorithm tends to misidentify cloud over snow as cloudfree, this could cause $F_{\text {cs }}^{C}(\mathrm{ObsWgt})$ to be biased high, resulting in a negative SW $\Delta^{C}$ adjustment. However, preliminary comparisons with the Cloud-Aerosol Lidar and Infrared Pathfinder Satellite Observations (CALIPSO; Winker et al. 2010) show no evidence that the MODIS cloud mask misidentifies clouds over snow as cloud-free (C. Yost et al. 2019, unpublished manuscript).

\section{b. $\Delta^{C}$ comparisons among different reanalyses}

The results in Figs. 1-3 are based upon $F_{\text {cs }}^{C}$ (CldRem) radiative transfer model calculations from the SYN1deg
Ed4.0 data product, which uses temperature, specific humidity, and ozone profiles from the GEOS-5.4.1 reanalysis (Rienecker et al. 2008), aerosol input from MATCH (Collins et al. 2001), and surface albedo and emissivity from Rutan et al. (2015). We compare the CERES SYN1deg-based adjustments with adjustments determined using radiative fluxes from the Modern-Era Retrospective Analysis for Research and Applications, version 2 (MERRA-2; Bosilovich et al. 2015; Gelaro et al. 2017), the European Centre for Medium-Range Weather Forecasts (ECMWF) interim reanalysis (ERAInterim; Dee et al. 2011) and ERA5 (Hersbach et al. 2018) for LW and SW for January 2008 (Figs. 4 and 5). In each case, we determine the $F_{\mathrm{cs}}^{C}(\mathrm{ObsWgt})$ using the same MODIS imager clear-sky fraction weights, so that differences between the various $\Delta^{C}$ adjustments are due solely to differences in $F_{\mathrm{cs}}^{C}(\mathrm{CldRem})$ from the various reanalyses. Figures $4 \mathrm{a}$ and $5 \mathrm{a}$ provide the mean January 2008 SYN1deg $\Delta^{C}$ adjustments for LW and SW, respectively, and Figs. 4b-d and 5b-d show the differences between adjustments from MERRA-2, ERA-Interim, and ERA5 and adjustments from SYN1deg.

In the LW, there is very good consistency between SYN1deg and the three reanalysis datasets (Figs. 4b-d). The magnitude of the global mean difference in $\Delta^{C}$ is $0.16 \mathrm{~W} \mathrm{~m}^{-2}$ or smaller, and the regional root-meansquare (RMS) difference $<1 \mathrm{~W} \mathrm{~m}^{-2}$ (Table 2). Over the Arctic Ocean, differences range from -3 to $-1 \mathrm{~W} \mathrm{~m}^{-2}$. We suspect these are due to differences in how skin temperatures are specified in SYN1deg compared to the reanalyses. In SYN1deg, skin temperature is specified using both MODIS imager-based skin temperature retrievals, which are only possible in cloud-free conditions, and skin temperatures in GEOS 5.4.1, available hourly. Since there is more confidence in the MODIS retrieval, SYN1deg anchors the diurnal cycle of GEOS 5.4.1 skin temperatures to the available MODIS imager-based skin temperature retrievals. In contrast, the skin temperatures from the reanalyses are a blend of model and assimilated satellite radiances. Arguably, for polar night, skin temperature determination is a challenge, which may be why the different methodologies used in SYN1deg and the reanalyses yield somewhat different $\Delta^{C}$ adjustments.

SW regional differences in $\Delta^{C}$ between SYN1deg and the three reanalyses are generally small over most of the globe (Figs. 5b-d). The global mean difference in $\Delta^{C}$ between MERRA-2 and SYN1deg is $-0.1 \mathrm{~W} \mathrm{~m}^{-2}$, but reaches $-0.55 \mathrm{~W} \mathrm{~m}^{-2}$ between ERA-Interim and SYN1deg (Table 2). The SW RMS differences are roughly twice as large as the LW RMS differences. This is mainly a result of very large SW $\Delta^{C}$ differences over some land areas (e.g., Asia) and off the coast of 
(a) $\Delta^{\mathrm{C}}$ (SYN1deg)

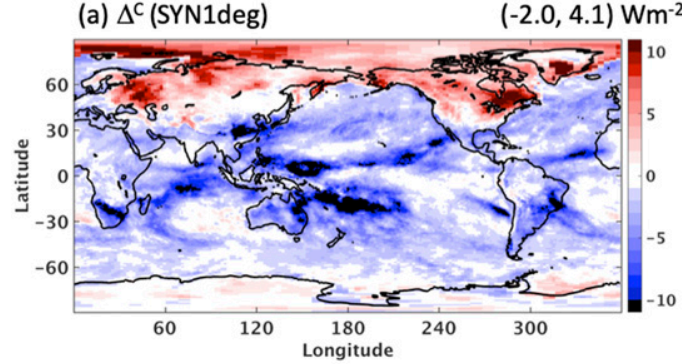

(c) $\Delta^{\mathrm{C}}$ (ERA-Interim) $-\Delta^{\mathrm{C}}$ (SYN1deg) $(0.11,0.79) \mathrm{Wm}^{-2}$

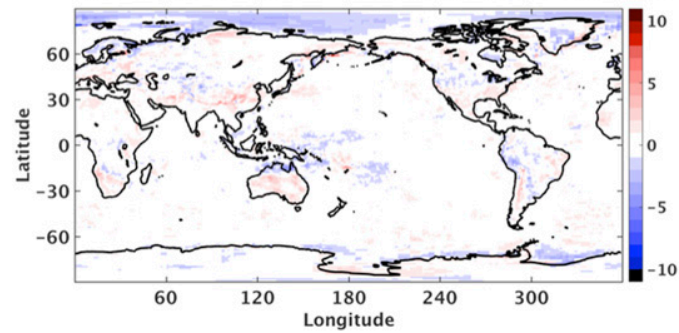

(b) $\Delta^{\mathrm{C}}$ (MERRA-2) $-\Delta^{\mathrm{C}}$ (SYN1deg)

$(0.16,0.95) \mathrm{Wm}^{-2}$

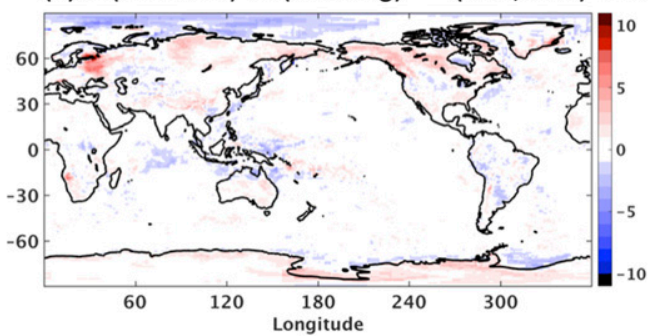

(d) $\Delta^{\mathrm{C}}$ (ERA5) $-\Delta^{\mathrm{C}}$ (SYN1deg)

$(0.04,0.87) \mathrm{Wm}^{-2}$

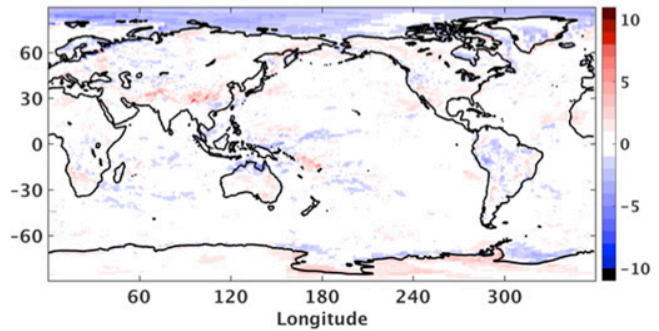

FIG. 4. (a) Regional mean LW $\Delta^{C}$ using CERES SYN1deg Ed4.0 computed TOA fluxes. (b) Difference between MERRA-2 LW $\Delta^{C}$ (MERRA-2) and $\Delta^{C}$ (SYN1deg). (c),(d) As in (b), but for (c) ERA-Interim and (d) ERA5. The same set of MODIS-observed clear-sky weights are used to determine $F_{\mathrm{cs}}^{C}$ (ObsWgt) from SYN1deg, MERRA-2, ERA-Interim, and ERA-5. Results are for January 2008. (Units: $\mathrm{W} \mathrm{m}^{-2}$.)

Antarctica. When only ocean regions equatorward of $60^{\circ}$ latitude are considered, the SW regional RMS differences are reduced by a factor of 2 (not shown). Over eastern China, the differences are mainly due to differences in how aerosol optical depths in SYN1deg and the three reanalyses vary with daily cloud cover. In SYN1deg, days with more cloud tend to have larger aerosol optical depths compared to days with fewer clouds, resulting in strongly positive $\mathrm{SW} \Delta^{C}$ values that reach $10 \mathrm{~W} \mathrm{~m}^{-2}$ (Fig. 5a). For MERRA-2, SW $\Delta^{C}$ exceed those from SYN1deg in this region, while the opposite is true for ERA-Interim, and to a lesser extent, ERA5. Differences are also evident over portions of Tibet and mountainous areas in central Asia. Off of Antarctica, (a) $\Delta^{\mathrm{C}}$ (SYN1deg)

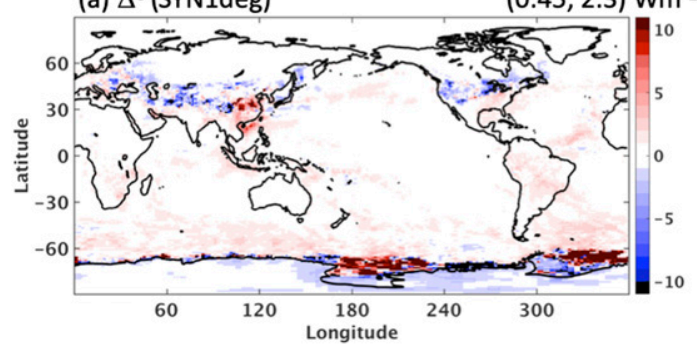

(c) $\Delta^{\mathrm{C}}$ (ERA-Interim) $-\Delta^{\mathrm{C}}$ (SYN1deg) $(-0.55,1.8) \mathrm{Wm}^{-2}$

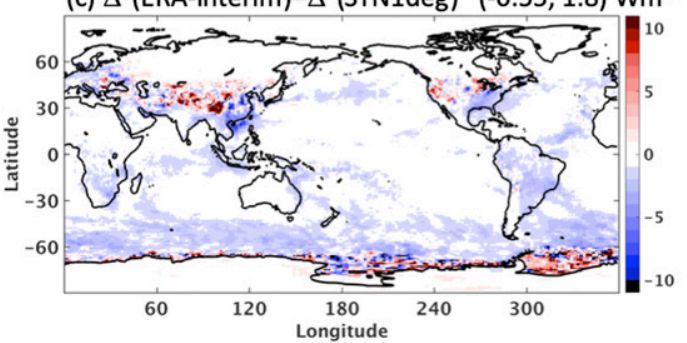

(b) $\Delta^{\mathrm{C}}$ (MERRA-2) $-\Delta^{\mathrm{C}}$ (SYN1deg) $(-0.1,1.5) \mathrm{Wm}^{-2}$

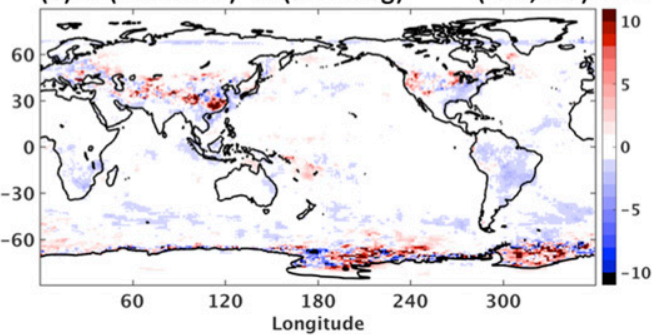

(d) $\Delta^{\mathrm{C}}$ (ERA5) $-\Delta^{\mathrm{C}}$ (SYN1deg) $\quad(-0.43,1.9) \mathrm{Wm}^{-2}$

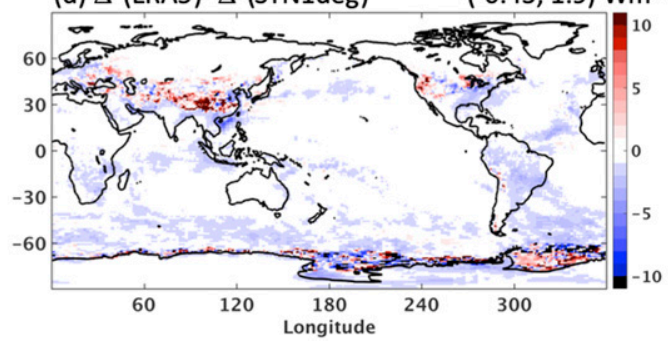

FIG. 5. As in Fig. 4, but for SW. (Units: $\mathrm{W} \mathrm{m}^{-2}$.) 
TABLE 2. Global mean and regional root-mean-square of $\Delta^{C}\left(\right.$ SYN1deg) at the TOA and differences in $\Delta^{C}$ from SYN1deg for MERRA-2, ERA-Interim, and ERA5 for January 2008.

\begin{tabular}{|c|c|c|}
\hline & \multicolumn{2}{|c|}{ Longwave } \\
\hline & Global mean $\left(\mathrm{W} \mathrm{m}^{-2}\right)$ & $\operatorname{RMS}\left(\mathrm{W} \mathrm{m}^{-2}\right)$ \\
\hline$\Delta^{C}($ SYN1deg $)$ & -2.0 & 4.1 \\
\hline$\Delta^{C}\left(\right.$ MERRA-2) $-\Delta^{C}$ (SYN1deg) & 0.16 & 0.95 \\
\hline$\Delta^{C}($ ERA-Interim $)-\Delta^{C}($ SYN1deg $)$ & 0.11 & 0.79 \\
\hline \multirow[t]{3}{*}{$\Delta^{C}$ (ERA5) $-\Delta^{C}$ (SYN1deg) } & 0.043 & 0.87 \\
\hline & \multicolumn{2}{|c|}{ Shortwave } \\
\hline & $\overline{\text { Global mean }\left(\mathrm{W} \mathrm{m}^{-2}\right)}$ & $\operatorname{RMS}\left(\mathrm{W} \mathrm{m}^{-2}\right)$ \\
\hline$\Delta^{C}($ SYN1deg $)$ & 0.45 & 2.3 \\
\hline$\Delta^{C}($ MERRA-2 $)-\Delta^{C}($ SYN1deg $)$ & -0.10 & 1.5 \\
\hline$\Delta^{C}($ ERA-Interim $)-\Delta^{C}($ SYN1deg $)$ & -0.55 & 1.8 \\
\hline$\Delta^{C}$ (ERA5) $-\Delta^{C}$ (SYN1deg) & -0.43 & 1.9 \\
\hline
\end{tabular}

SYN1deg SW $\Delta^{C}$ values are also quite large, and there are large differences between SYN1deg and the three reanalyses. This is likely due to the different input datasets used for sea ice concentration in the various calculations. CERES SYN1deg relies on a combination of the National Snow and Ice Data Center (NSIDC) NearReal-Time Snow and Ice Extent (NISE) product (Brodzik and Stewart 2016), the National Environmental Satellite, Data, and Information Service (NESDIS) snow/ice map, and the CERES team's snow and sea ice fraction over the clear portions of CERES footprints (Minnis et al. 2008). In contrast, MERRA-2 and the ECMWF reanalyses use the Operational Sea Surface Temperature and Sea Ice Analysis (OSTIA) from Donlon et al. (2012). Over open ocean there is good agreement in SW $\Delta^{C}$ between SYN1deg and both MERRA-2 (Fig. 5b) and ERA5 (Fig. 5d), but larger differences with ERA-Interim (Fig. 5c), particularly over the Southern Ocean region.

\section{c. Annual cycle of climatological mean cloud radiative effect}

After applying the SYN1deg $\Delta^{C}$ adjustments, the global climatological mean LW, SW, and net CRE change, and the magnitudes of the changes vary seasonally (Figs. 6a-f). In the LW, the 10-yr global mean CRE climatology for July $2005-J u n e ~ 2015$ is $25.7 \mathrm{~W} \mathrm{~m}^{-2}$ with the $\Delta^{C}$ adjustment (Table 3 ). This corresponds to a global $2.2 \mathrm{~W} \mathrm{~m}^{-2}$ reduction compared to the case in which no adjustment is applied, but the reduction varies from $2.0 \mathrm{~W} \mathrm{~m}^{-2}$ in February to $2.4 \mathrm{~W} \mathrm{~m}^{-2}$ in May (Fig. 6b). The global mean SW CRE is $-45.3 \mathrm{~W} \mathrm{~m}^{-2}$ after applying the $\Delta^{C}$ adjustment, corresponding to a $0.5 \mathrm{~W} \mathrm{~m}^{-2}$ reduction in TOA radiative cooling by clouds compared to the EBAF value with no adjustment. The smallest reduction of $0.3 \mathrm{~W} \mathrm{~m}^{-2}$ occurs in April and the largest reduction of $0.8 \mathrm{~W} \mathrm{~m}^{-2}$ occurs during June (Fig. $6 \mathrm{~d}$ ). The latter is likely due to a larger aerosol influence on the $\Delta^{C}$ adjustment resulting from increased insolation during boreal summer. The corresponding global mean net CRE is $-19.6 \mathrm{~W} \mathrm{~m}^{-2}$, which implies a stronger cloud radiative cooling effect of $1.7 \mathrm{~W} \mathrm{~m}^{-2}$ compared to the original EBAF value. The change ranges from $1.4 \mathrm{~W} \mathrm{~m}^{-2}$ in July to nearly $2.0 \mathrm{~W} \mathrm{~m}^{-2}$ in April and May.

At the surface, the $\Delta^{C}$ adjustment enhances clear-sky downward LW flux by $3.3 \mathrm{~W} \mathrm{~m}^{-2}$ and reduces clear-sky downward SW flux by $2.3 \mathrm{~W} \mathrm{~m}^{-2}$ (Table 3 ). The positive difference in the LW is due to the tendency for moister conditions under cloudy conditions, resulting in enhanced downward clear-sky flux after removing the clouds in the calculation. In the SW, the higher humidity and aerosol concentration has the opposite effect. Since the $\Delta^{C}$ adjustment is much smaller for the upward SW and LW fluxes, cancellation between the SW and LW adjustments results in a smaller overall impact for clearsky SW + LW net flux $\left(0.8 \mathrm{~W} \mathrm{~m}^{-2}\right)$.

\section{d. Interannual variations}

To examine the impact of the $\Delta^{C}$ adjustments on interannual variations in CRE, we compare deseasonalized monthly anomalies in global mean $\Delta^{C}$ adjustments with anomalies in CRE (after applying the $\Delta^{C}$ adjustment) for LW and SW (Figs. 7a,b). We focus on July 2002 onward since that is the part of the CERES EBAF record when both CERES Terra and Aqua data are available, resulting in smaller uncertainties. In the SW, anomalies in $\Delta^{C}$ adjustments are much smaller than CRE anomalies (Fig. 7b). The standard deviation in $\mathrm{SW} \Delta^{C}$ anomalies is $0.069 \mathrm{~W} \mathrm{~m}^{-2}$, while it is $0.51 \mathrm{~W} \mathrm{~m}^{-2}$ for SW CRE. In the LW, the magnitudes are much closer (Fig. 7a), with a LW $\Delta^{C}$ anomaly standard deviation of $0.11 \mathrm{~W} \mathrm{~m}^{-2}$ compared to $0.28 \mathrm{~W} \mathrm{~m}^{-2}$ for $\mathrm{LW}$ CRE anomalies. Interestingly, there is a sudden dip in LW $\Delta^{C}$ anomalies between July 2015 and August 2016 in which 
(a) LW CRE

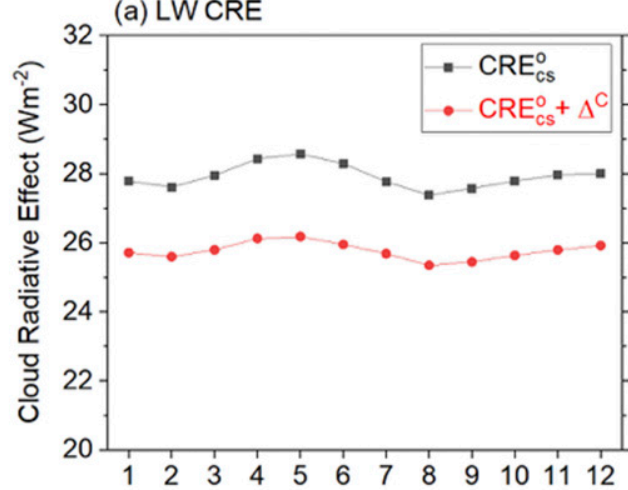

(c) SW CRE

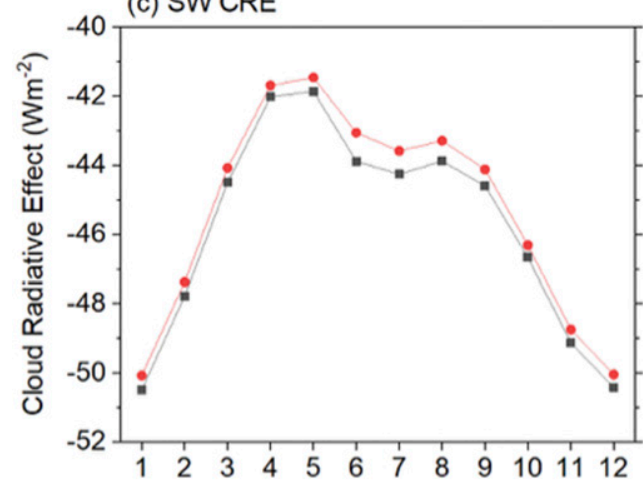

(e) Net CRE

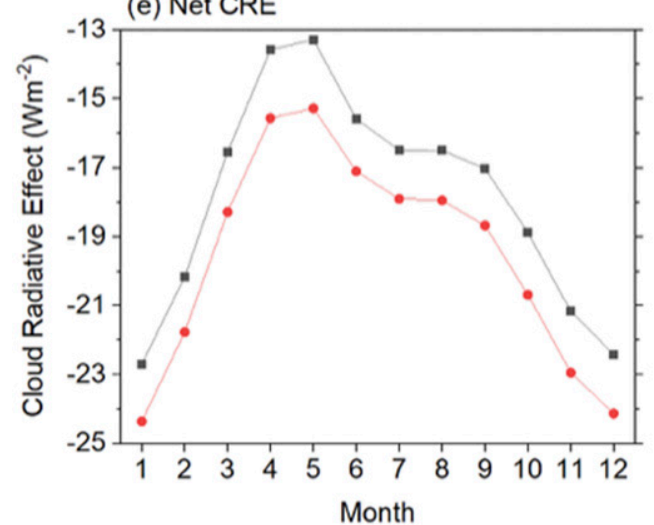

(b) $L W \Delta^{c}$

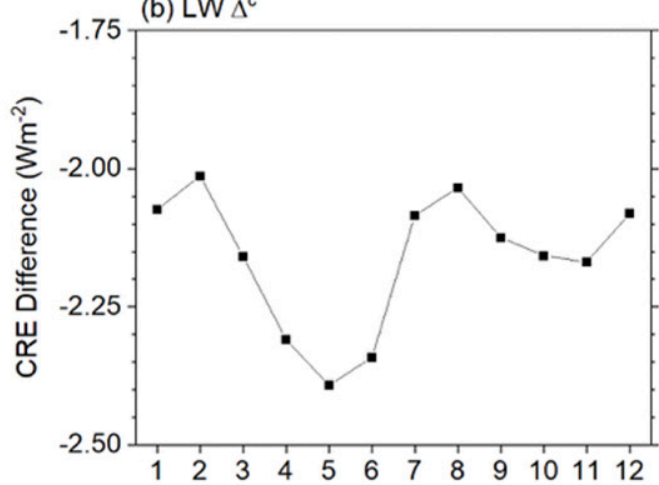

(d) $S W \Delta^{c}$
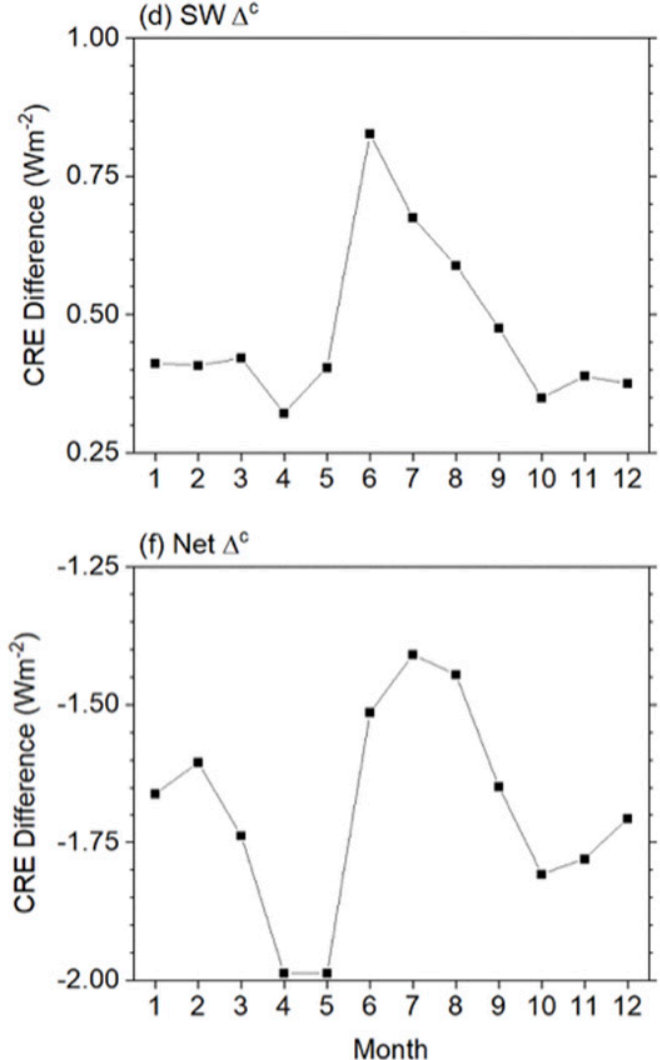

FIG. 6. Climatological monthly global mean cloud radiative effect for (a) LW, (c) SW, and (e) Net radiation at TOA and magnitude of $\Delta^{C}$ for (b) LW, (d) SW, and (f) Net. Climatological means are determined for July 2005-June 2015.

anomalies remain less than $-0.10 \mathrm{~W} \mathrm{~m}^{-2}$ and reach as low as $-0.36 \mathrm{~W} \mathrm{~m}^{-2}$. This period includes the buildup to the 2015/16 El Niño, its peak, and the months that immediately follow. LW anomalies in the individual components of $\Delta^{C}\left[F_{\mathrm{cs}}^{C}(\mathrm{CldRem})\right.$ and $\left.F_{\mathrm{cs}}^{c}(\mathrm{ObsWgt})\right]$ are both strongly positive during the peak of the El Niño, reaching as high as $1.5 \mathrm{~W} \mathrm{~m}^{-2}$ (not shown). It turns out that during the peak of the El Niño, the anomaly increases in $F_{\mathrm{cs}}^{c}(\mathrm{ObsWgt})$ exceed those in $F_{\mathrm{cs}}^{C}(\mathrm{CldRem})$, leading to negative anomalies in $\mathrm{LW} \Delta^{C}$. This is likely because there is also an increase in cloud fraction anomalies, thereby increasing the "dry bias" in $F_{\mathrm{cs}}^{c}(\mathrm{ObsWgt})$ relative to $F_{\text {cs }}^{C}($ CldRem $)$.

We compare the regional distribution of interannual variations in LW and SW $\Delta^{C}$ adjustments with the corresponding LW and SW CRE variations in Figs. 8a-d, which shows the regional standard deviation in deseasonalized monthly anomalies for July 2002-September 2018. LW standard deviations in both CRE and $\Delta^{C}$ reach maximum values over the west tropical Pacific (Figs. 8a,c). For LW CRE, standard deviations are typically between 15 and $18 \mathrm{~W} \mathrm{~m}^{-2}$ while they remain between 2 and $3 \mathrm{~W} \mathrm{~m}^{-2}$ for 
TABLE 3. Global mean clear-sky fluxes and CREs for July 2005-June 2015 ( $\left.\mathrm{W} \mathrm{m}^{-2}\right)$.

\begin{tabular}{|c|c|c|c|c|}
\hline & & \multicolumn{3}{|c|}{ Top of atmosphere } \\
\hline & & EBAF (no adjustment) & EBAF with $\Delta^{C}$ adjustment & Difference \\
\hline Solar insolation & & 340.0 & 340.0 & 0.0 \\
\hline \multirow[t]{3}{*}{ Clear sky } & LW & 268.1 & 265.9 & -2.2 \\
\hline & SW & 53.3 & 53.8 & 0.5 \\
\hline & Net & 18.6 & 20.3 & 1.7 \\
\hline \multirow{5}{*}{ CRE } & LW & 27.9 & 25.7 & -2.2 \\
\hline & SW & -45.8 & -45.3 & 0.5 \\
\hline & Net & -17.9 & -19.6 & -1.7 \\
\hline & & \multicolumn{3}{|c|}{ Surface } \\
\hline & & EBAF (no adjustment) & EBAF with $\Delta^{C}$ adjustment & Difference \\
\hline \multirow[t]{7}{*}{ Clear sky } & LW down & 313.9 & 317.2 & 3.3 \\
\hline & LW up & 397.6 & 398.2 & 0.6 \\
\hline & LW net & -83.7 & -81.0 & 2.7 \\
\hline & SW down & 243.0 & 240.7 & -2.3 \\
\hline & SW up & 29.5 & 29.1 & -0.4 \\
\hline & SW net & 213.5 & 211.6 & -1.9 \\
\hline & $\mathrm{SW}+\mathrm{LW}$ net & 129.8 & 130.6 & 0.8 \\
\hline \multirow[t]{7}{*}{ CRE } & LW down & 30.9 & 27.6 & -3.3 \\
\hline & LW up & -0.75 & -0.15 & 0.6 \\
\hline & LW net & 30.2 & 27.5 & -2.7 \\
\hline & SW down & -56.4 & -54.1 & 2.3 \\
\hline & SW up & 6.3 & 5.9 & -0.4 \\
\hline & SW net & -50.1 & -48.2 & 1.9 \\
\hline & $\mathrm{SW}+\mathrm{LW}$ net & -19.9 & -20.7 & -0.8 \\
\hline
\end{tabular}

$\Delta^{C}$. In the SW, standard deviations in CREs over this region reach $25 \mathrm{~W} \mathrm{~m}^{-2}$, but remain $<1 \mathrm{~W} \mathrm{~m}^{-2}$ for $\Delta^{C}$. In contrast, the variability in $\mathrm{SW} \Delta^{C}$ is much greater over the sea ice region off the coast of Antarctica. In that case, the standard deviation in $\Delta^{C}$ anomalies is of order $10 \mathrm{~W} \mathrm{~m}^{-2}$, which is roughly half the magnitude of those for CRE. Given the larger differences in SW anomalies over this region between SYN1deg and the reanalyses considered in Fig. 5, it follows that there is greater uncertainty in CRE variations over the sea ice off Antarctica compared to other regions.

\section{e. Comparison with climate models}

The $\Delta^{C}$ adjustments have important implications for comparisons of CRE between observations and climate model simulations. To illustrate, we compare CERES EBAF TOA CRE with and without the $\Delta^{C}$ adjustments with seven phase 6 of the Coupled Model Intercomparison Project fully coupled historical simulations (Eyring et al. 2016), listed in Table 4. We consider the period from 2003 to 2014. The CMIP6 simulation output are spatially interpolated onto the CERES $1^{\circ} \times 1^{\circ}$ latitude-longitude grid. Figure 9a shows that the LW $\Delta^{C}$ adjustment brings the CERES and multimodel mean LW CREs into much better agreement compared to the case in which no $\Delta^{C}$ adjustment is applied. The CERES result with the $\Delta^{C}$ adjustment lies within one standard deviation of the multimodel mean in most of the latitude bands. In fact, for $75^{\circ}$ to $90^{\circ} \mathrm{N}$, where the LW $\Delta^{C}$ adjustment shifts from being negative to positive, the bias between the multimodel and CERES EBAF is removed entirely after applying the $\Delta^{C}$ adjustment. Globally, the multimodel mean LW CRE is $24.8 \mathrm{~W} \mathrm{~m}^{-2}$ (with a standard deviation of $3 \mathrm{~W} \mathrm{~m}^{-2}$ ), compared to $25.7 \mathrm{~W} \mathrm{~m}^{-2}$ for CERES EBAF with the LW $\Delta^{C}$ adjustment.

LW CRE regional comparisons between the multimodel mean and CERES show where marked improvements occur when the $\Delta^{C}$ adjustment is applied to CERES EBAF. Figure 10a shows the climatological mean LW CRE for CERES EBAF (with the $\Delta^{C}$ adjustment) while Figs. 10b and 10c show differences between the multimodel mean LW CRE and CERES EBAF with and without the $\Delta^{C}$ adjustment, respectively. Including the $\Delta^{C}$ adjustment has the greatest impact on model-CERES LW CRE differences in the west tropical Pacific, along the ITCZ, the SPCZ, and the Indian Ocean. In these regions the negative biases are less pronounced when the $\Delta^{C}$ adjustment is included. In contrast, positive biases over the central and eastern Pacific just south of the equator are increased slightly after including the $\Delta^{C}$ adjustment. Overall, the regional RMS model-CERES difference with the adjustment is $4.5 \mathrm{~W} \mathrm{~m}^{-2}$, compared to $6.1 \mathrm{~W} \mathrm{~m}^{-2}$ without it.

In the SW (Fig. 9b), the multimodel mean SW CRE is more pronounced (more negative) compared to CERES 
(a) LW

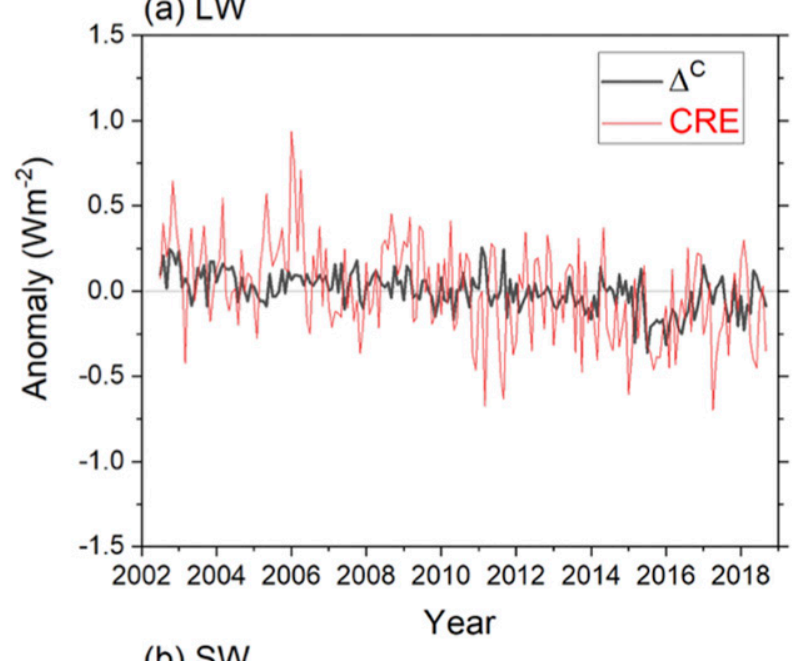

(b) SW

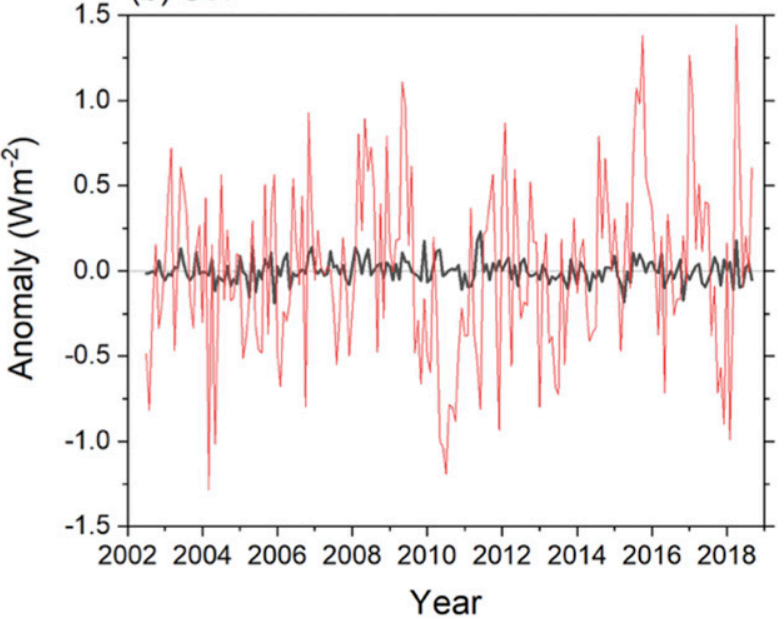

FIG. 7. Anomalies in global mean TOA adjustment $\left(\Delta^{C}\right)$ and CRE (after applying the $\Delta^{C}$ adjustment) for (a) LW and (b) SW for July 2002-September 2018.

EBAF in most latitude bands. In this case the SW $\Delta^{C}$ adjustment has negligible impact on the comparison. The global multimodel mean SW CRE is $-49 \mathrm{~W} \mathrm{~m}^{-2}$, with a standard deviation of $5 \mathrm{~W} \mathrm{~m}^{-2}$, and the global mean is $-45.3 \mathrm{~W} \mathrm{~m}^{-2}$ for CERES EBAF with the $\Delta^{C}$ adjustment.

The multimodel mean net CRE shows stronger radiative cooling compared to CERES, particularly between $60^{\circ} \mathrm{S}$ and $60^{\circ} \mathrm{N}$ (Fig. 9c). The global mean net CRE for the multimodel mean is $-24.5 \mathrm{~W} \mathrm{~m}^{-2}$ (with a standard deviation of $4 \mathrm{~W} \mathrm{~m}^{-2}$ ) compared to $-19.5 \mathrm{~W} \mathrm{~m}^{-2}$ for CERES EBAF after applying the SW and LW $\Delta^{C}$ adjustments.

\section{Uncertainty}

a. TOA

Loeb et al. (2018) provide estimates of uncertainties $(1 \sigma)$ in CERES EBAF Ed4.0 monthly $1^{\circ} \times 1^{\circ}$ latitude- longitude SW, LW, and net TOA radiative fluxes for all-sky, clear-sky, and CRE (see their Table 8). They include all known sources of uncertainty (e.g., calibration, scene identification, radiance-to-flux conversion, diurnal adjustment) and combine them assuming they are independent, so the total uncertainty is given by the square root of the sum of squares of the individual contributions. Here we revisit the uncertainties, accounting for uncertainties in the $\Delta^{C}$ adjustments as well. For all-sky, uncertainties are the same as those in Loeb et al. (2018) since the $\Delta^{C}$ adjustments have no impact on all-sky flux. For clear-sky and CRE, we add the regional uncertainties in the $\Delta^{C}$ adjustments to the existing Loeb et al. (2018) values. We assume the regional uncertainty in the $\mathrm{SW}$ and $\mathrm{LW} \Delta^{C}$ adjustments to be 2 and $1 \mathrm{~W} \mathrm{~m}^{-2}$, respectively, and assume these uncertainties are independent of other sources of uncertainty. The $\Delta^{C}$ adjustment uncertainties are based upon the RMS differences between the $\Delta^{C}$ adjustments using SYN1deg and the reanalyses in Table 2. Regional uncertainties in clear-sky SW and LW TOA flux are approximately $5 \mathrm{~W} \mathrm{~m}^{-2}$, twice those for all sky. The larger clear-sky uncertainty is due to the additional uncertainty associated with identifying cloud-free scenes using the MODIS imager. Uncertainties in regional monthly CREs are determined from all-sky, clear-sky, and $\Delta^{C}$ adjustment uncertainties, accounting for the correlation in calibration uncertainty between all sky and clear sky (Loeb et al. 2018).

The uncertainties in Table 5 correspond to the overall regional uncertainty when all $1^{\circ} \times 1^{\circ}$ latitude-longitude regions are considered. However, we expect SW uncertainties to be larger in certain locations, such as in high-latitude regions over sea ice off the coast of Antarctica and for regions over land with high aerosol loadings (e.g., eastern China). In the LW, regional uncertainties in clear-sky flux and CREs are larger at high latitudes due primarily to the greater challenge associated with clear-sky scene identification from passive sensors, particularly during polar night.

\section{b. Surface}

Uncertainties in surface fluxes under all-sky conditions are provided in Kato et al. (2018). To estimate clear-sky downward flux uncertainty, we analyze coincident computed and measured surface fluxes at 36 ground sites and 46 ocean buoys for the period between March 2000 and October 2018. Land sites and ocean buoys are predominately located in the midlatitude and tropics, respectively (see Kato et al. 2018). Because clear-sky conditions do not persist for the entire month at any given site, we use hourly surface flux measurements that coincide with Terra and/or Aqua observation times. We select clear-sky fluxes based upon MODIS 
(a) Standard Deviation in LW $\Delta^{c}$ Anomaly

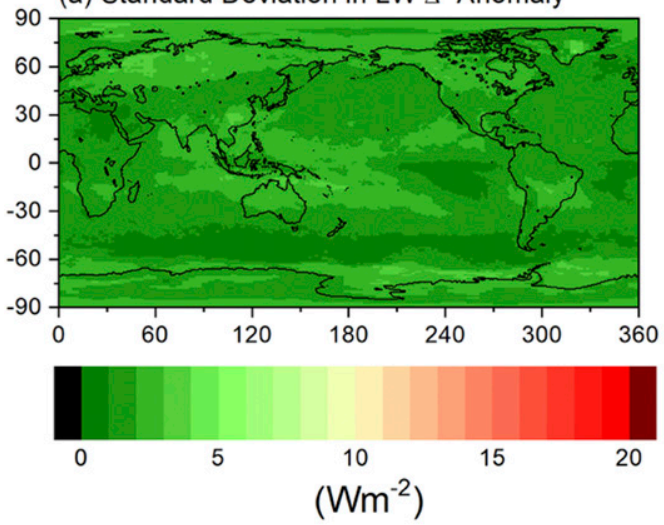

(c) Standard Deviation in LW CRE Anomaly

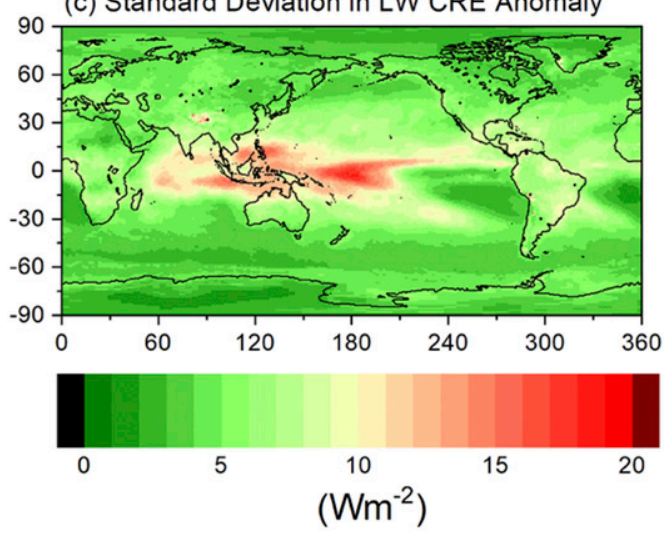

(b) Standard Deviation in SW $\Delta^{\mathrm{c}}$ Anomaly

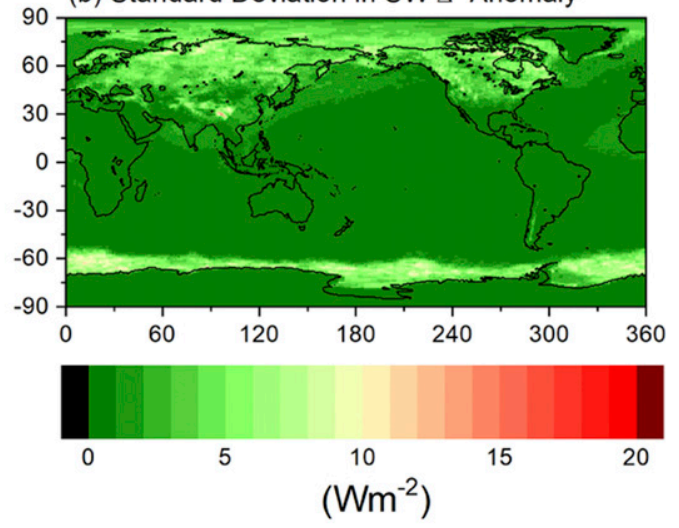

(d) Standard Deviation in SW CRE Anomaly

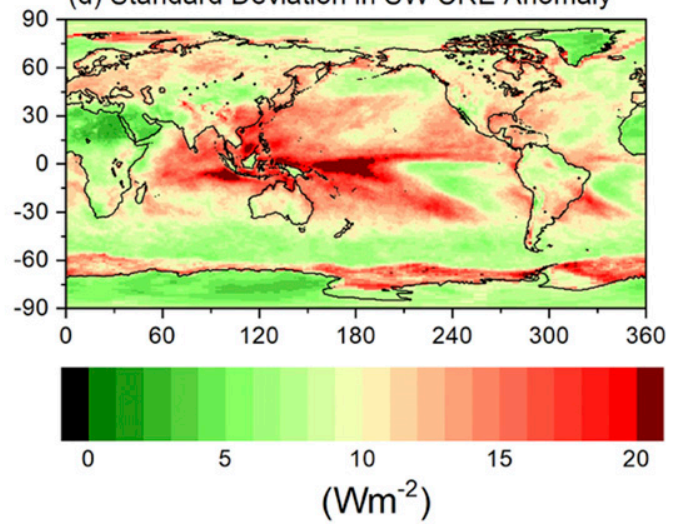

FIG. 8. Standard deviation in regional anomalies of (a) LW and (b) SW $\Delta^{C}$ adjustments and anomalies of (c) LW and (d) SW CRE for July 2002-September 2018.

cloud fraction with a threshold of zero cloud cover over the grid box where each ground site is located. Land sites are separated into three regional groups, according to whether they are from the Atmospheric Radiation Measurement (ARM) program (Ackerman and Stokes 2003), the Surface Radiation Budget Observing Network (SURFRAD; Augustine et al. 2000), or the Baseline Surface Radiation Network (BSRN; Ohmura et al. 1998; Driemel et al. 2018). In the SW, there are between 3000 and 5000 matched pairs of computed and measured surface fluxes for all sites within a group (it is roughly double that for $\mathrm{LW}$ since $\mathrm{LW}$ includes nighttime as well). For each group, a bias and standard deviation is calculated from all matched pairs over the entire period. The monthly mean bias for a group is assumed equal to the bias of all matched pairs and the standard error in the monthly mean bias is calculated from the standard deviation of all matched pairs divided by the square root of 30 . The monthly mean bias and standard error are then divided by the overall mean of all matched pairs, and these are then multiplied by the global monthly mean land flux. This is equivalent to assuming the relative uncertainty is spatially and temporally constant. The root-mean-square difference (RMSD) between computed and measured fluxes for the group are determined from the square root of the sum of the squares of the mean bias and standard error. This process is repeated for each land group, which are then combined by weighting their RMSDs by the number of sites in a group. The RMSD for ocean buoy sites is computed in the same way except that only one group is used because almost all buoys are located in tropics. The ocean and land RMSDs

TABLE 4. List of CMIP6 models.

\begin{tabular}{lllc}
\hline \hline & \multicolumn{1}{c}{ Model } & \multicolumn{1}{c}{ Country } & $\begin{array}{c}\text { Horizontal resolution } \\
(\text { lon } \times \text { lat })\end{array}$ \\
\hline 1 & BCC-CSM2-MR & China & $1.125 \times 1.12$ \\
2 & BCC-ESM1 & China & $2.8125 \times 2.79$ \\
3 & CESM2 & United States & $1.25 \times 0.94$ \\
4 & CESM2-WACCM & United States & $1.25 \times 0.94$ \\
5 & GISS-E2-1-G & United States & $2.5 \times 2.0$ \\
6 & IPSL-CM6A-LR & France & $2.5 \times 1.27$ \\
7 & MRI-ESM2.0 & Japan & $1.125 \times 1.12$ \\
\hline
\end{tabular}




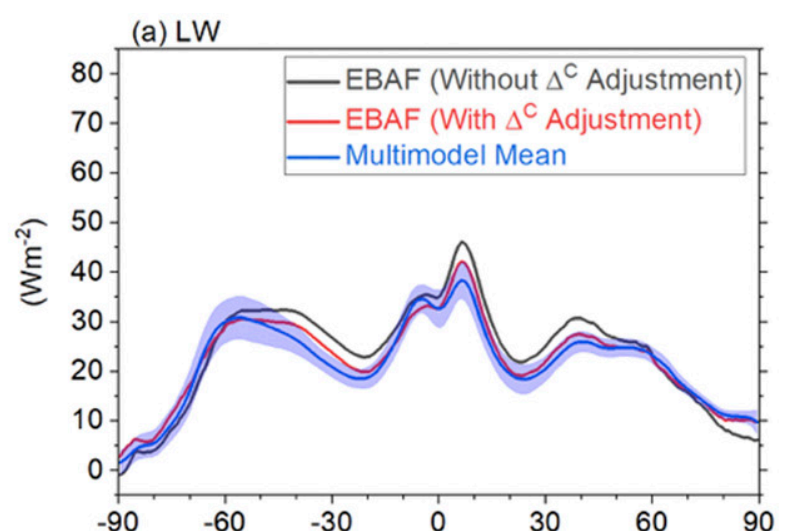

(b) SW
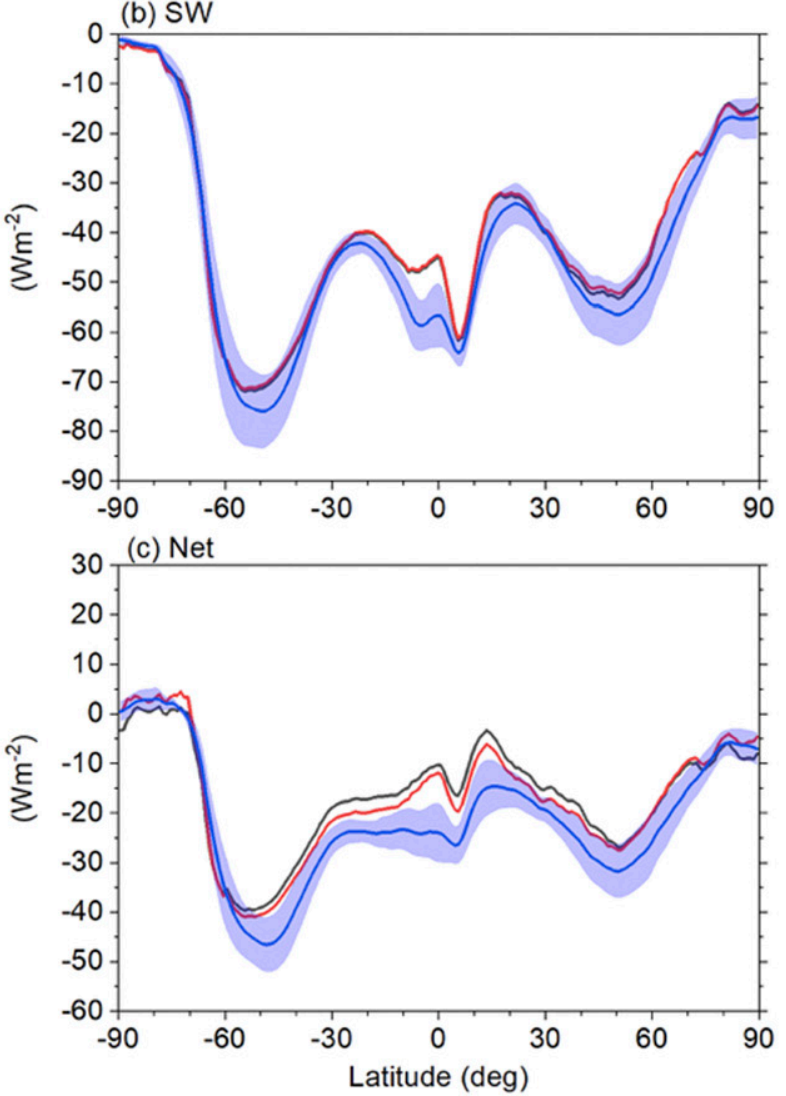

FIG. 9. Comparison of TOA (a) LW, (b) SW, and (c) Net CRE for CERES EBAF with and without the $\Delta^{C}$ adjustment and for a multimodel mean of 7 CMIP6 models. Period of coverage 2003-14. Shading corresponds to \pm 1 standard deviation from the multimodel mean.

are then combined to determine a global RMSD by area weighting the ocean and land values. Because the uncertainties in monthly mean downward surface LW and SW fluxes measured at the surface sites are both approximately $5 \mathrm{~W} \mathrm{~m}^{-2}$ (Michalsky et al. 1999; Gröbner et al. 2014), we add the surface measurement uncertainties in quadrature with the global RMSDs to estimate the overall SW and LW uncertainties. (a) CERES EBAF LW CRE (with $\Delta^{c}$ Adjustment)

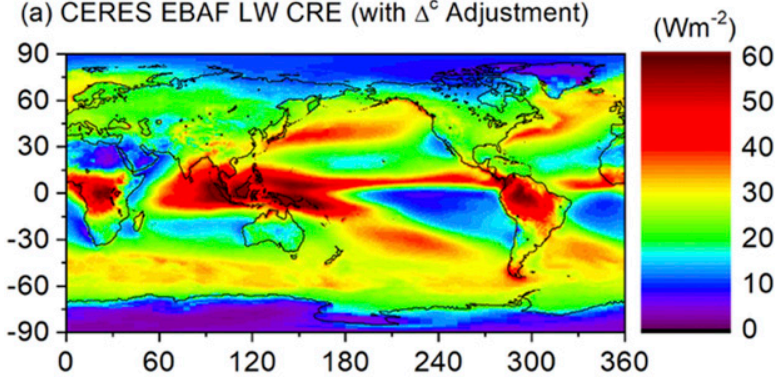

(b) Multi-Model minus EBAF (with $\Delta^{\mathrm{c}}$ Adjustment)

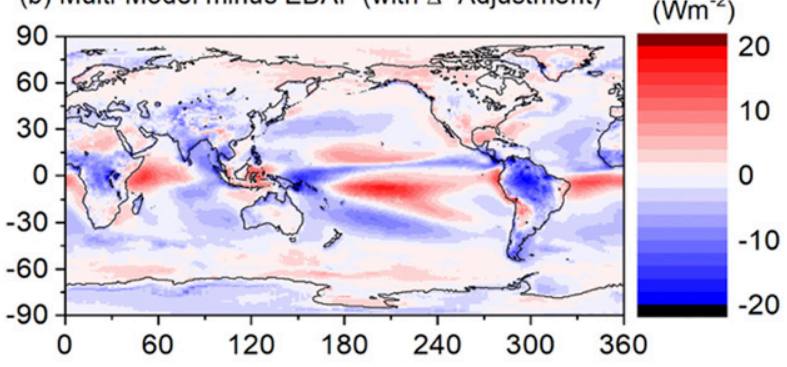

(c) Multi-Model minus EBAF (Without $\Delta^{\mathrm{c}}$ Adjustment) $\left(\mathrm{Wm}^{-2}\right)$

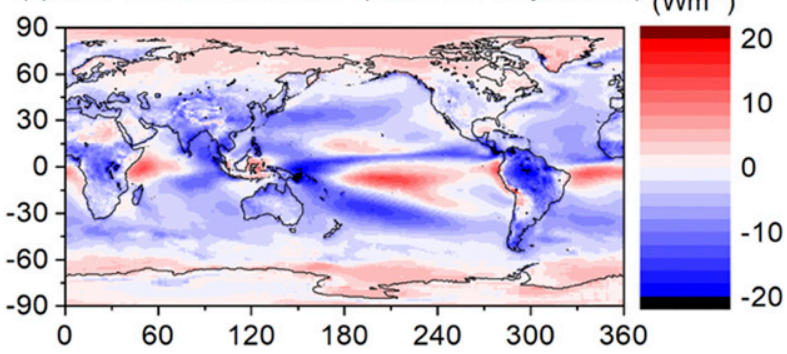

FIG. 10. Comparison of TOA LW CRE for multimodel mean of 7 CMIP6 models and CERES EBAF with and without the LW $\Delta^{C}$ adjustment. (a) Mean LW CRE for CERES EBAF with adjustment. Difference between multimodel mean LW CRE and (b) CERES EBAF with $\mathrm{LW} \Delta^{C}$ adjustment and (c) without $\mathrm{LW} \Delta^{C}$ adjustment.

The resulting regional uncertainties in clear-sky surface downward fluxes are $6 \mathrm{~W} \mathrm{~m}^{-2}$ for $\mathrm{SW}$ and $8 \mathrm{~W} \mathrm{~m}^{-2}$ for LW (Table 5). In the LW, the uncertainties for all sky and clear sky are comparable, but for SW the all-sky uncertainty is over a factor of 2 larger than clear sky. For the regional uncertainty in the clear-sky upward SW and LW fluxes, we assume that the uncertainty is the same as the all-sky uncertainty because the uncertainty in surface albedo, emissivity, and surface skin temperature are largely contributing the upward flux uncertainty.

Regional uncertainties in surface net flux, SW + LW flux, and CRE are determined by accounting for the upward and downward flux uncertainties and their covariance. We compute the latter using surface flux adjustments applied to computed fluxes when CERESderived TOA fluxes are used to constrain surface fluxes. In the process, surface, atmosphere, cloud, and aerosol 
TABLE 5 . Uncertainty in $1^{\circ} \times 1^{\circ}$ regional monthly TOA and surface fluxes and CREs for SW, LW, and net $\left(\mathrm{W} \mathrm{m}^{-2}\right)$.

\begin{tabular}{lccr}
\hline \hline & \multicolumn{3}{c}{ TOA } \\
\cline { 2 - 4 } & All sky & Clear sky & CRE \\
\hline SW & 2.5 & 5.4 & 5.9 \\
LW & 2.5 & 4.6 & 4.5 \\
Net & 3.5 & 7.1 & 7.4 \\
& & Surface & \\
\cline { 2 - 4 } & All sky & Clear sky & CRE \\
\cline { 2 - 4 } LW down & 9 & 8 & 9 \\
LW up & 15 & 15 & 17 \\
LW net & 17 & 17 & 18 \\
SW down & 14 & 6 & 14 \\
SW up & 11 & 11 & 14 \\
SW net & 13 & 13 & 26 \\
SW + LW net & 20 & 21 & \\
\hline
\end{tabular}

properties are adjusted to match computed TOA fluxes with TOA fluxes derived from CERES observations (Kato et al. 2018). Based on the adjustment of these properties, surface SW and LW upward and downward fluxes are also adjusted. Therefore, surface flux adjustments are considered to be the error in the surface fluxes due to errors in inputs used in the computation. Temporal error correlations are derived from regional surface flux adjustments averaged over the entire globe using the time period from March 2000 through February 2016. Regional uncertainties are $18 \mathrm{~W} \mathrm{~m}^{-2}$ for $\mathrm{LW}$ net downward flux, $16 \mathrm{~W} \mathrm{~m}^{-2}$ for SW net downward flux, and $26 \mathrm{~W} \mathrm{~m}^{-2}$ for SW + LW Net (Table 5).

\section{Summary}

A key quantity in climate model evaluation is cloud radiative effect (CRE), defined as the difference between the radiative flux in the presence of cloud and that under clear-sky conditions. However, the manner in which clear sky is defined in observations differs markedly from that used in climate models. In observations, clear-sky fluxes are determined only from areas within a grid box identified as cloud free. In climate models, clear-sky fluxes are determined over the entire grid box, ignoring any clouds within the atmospheric column. The discrepancy can lead to some large regional differences in CRE because the atmospheric and surface properties in a cloudy column can differ substantially from those for a clear column.

In this paper, we introduced a new method to overcome the disparity between observed and model definitions of clear-sky by applying adjustment factors to observed monthly mean CERES EBAF SW, LW, and net clear-sky TOA and surface fluxes, significantly improving comparisons between observed and model
CREs. This addresses a long-standing inconsistency between models and observations of CRE. The adjustment factors are given by the difference between calculated clear-sky fluxes obtained by ignoring clouds in the atmospheric column and those obtained by cleararea weighting the clear-sky fluxes. The calculated clearsky fluxes are taken from the CERES SYN1deg product (Rutan et al. 2015) and clear-area weights are inferred from MODIS imager cloud fractions in the CERES SSF1deg product. The clear-area weighting is applied hourly and averaged monthly for $1^{\circ} \times 1^{\circ}$ latitudelongitude regions over the globe.

The LW TOA adjustment factors are generally negative everywhere except at high latitudes between winter and fall. They are pronounced in the tropics (reaching $-12 \mathrm{~W} \mathrm{~m}^{-2}$ ) in regions with high uppertropospheric humidity and cirrus cloud cover because calculated fluxes determined by ignoring clouds in the atmospheric column have a larger relative contribution from the colder upper layers of the atmosphere compared to clear-area weighted fluxes, which tend to occur in drier conditions and therefore have a larger contribution from the surface. Tropical regions with pronounced LW TOA adjustment factors include the west tropical Pacific, SPCZ, and ITCZ. Positive LW adjustment factors occur during winter at high latitudes because surface and boundary layer air temperatures tend to be warmer when clouds are present owing to their strong greenhouse effect. Globally, the average LW TOA adjustment factor is $-2.2 \mathrm{~W} \mathrm{~m}^{-2}$. At the surface, the global mean adjustment factor for net downward $\mathrm{LW}$ flux is $2.7 \mathrm{~W} \mathrm{~m}^{-2}$. The TOA SW adjustment factor is generally much weaker in magnitude compared to the LW adjustment. Its global average is $0.5 \mathrm{~W} \mathrm{~m}^{-2}$, but it can reach close to $10 \mathrm{~W} \mathrm{~m}^{-2}$ in regions of sea ice off the coast of Antarctica and in regions of heavy aerosol, such as over eastern China.

To get a sense of how robust the SW and LW adjustment factors are to the meteorological assimilation system used, adjustment factors determined using SYN1deg clear-sky TOA fluxes are compared with those from MERRA-2, ERA-Interim, and ERA5 for one month (January 2008). In each case, the same MODIS-based clear area weights are used. In the LW, the $1^{\circ}$ regional RMS difference between adjustment factors from the different reanalyses and SYN1deg is $<1 \mathrm{~W} \mathrm{~m}^{-2}$. Differences are generally between -3 to $-1 \mathrm{~W} \mathrm{~m}^{-2}$ over the Arctic Ocean, likely due to skin temperature differences among the various datasets. In the SW, regional RMS differences are twice as large as for LW due primarily to discrepancies in regions of heavy aerosol and sea ice off of Antarctica. For nonpolar ocean regions, regional RMS differences are $<1 \mathrm{~W} \mathrm{~m}^{-2}$. 
When the SW and LW adjustment factors are applied, the global mean TOA CRE becomes $25.7 \mathrm{~W} \mathrm{~m}^{-2}$ for $\mathrm{LW},-45.3 \mathrm{~W} \mathrm{~m}^{-2}$ for $\mathrm{SW}$, and $-19.6 \mathrm{~W} \mathrm{~m}^{-2}$ for net. These correspond to differences of $-2.2,0.5$, and $-1.7 \mathrm{~W} \mathrm{~m}^{-2}$, respectively, compared to CRE values when no adjustment is applied. However, the magnitude of the differences is dependent upon season. The seasonal dependence is $0.4 \mathrm{~W} \mathrm{~m}^{-2}$ in the $\mathrm{LW}, 0.5 \mathrm{~W} \mathrm{~m}^{-2}$ in the $\mathrm{SW}$, and $0.6 \mathrm{~W} \mathrm{~m}^{-2}$ for net. At the surface, the global mean CRE is $27.5 \mathrm{~W} \mathrm{~m}^{-2}$ for LW net, $-48.2 \mathrm{~W} \mathrm{~m}^{-2}$ for SW net, and $-20.7 \mathrm{~W} \mathrm{~m}^{-2}$ for total net CRE, corresponding to differences of $-2.7,1.9$, and $-0.8 \mathrm{~W} \mathrm{~m}^{-2}$, respectively, compared to the corresponding values with no adjustment factor. Interannual variations in the SW and LW adjustment factor are found to be much smaller compared to those in CRE, particularly at regional scales. The largest interannual variations in the adjustment factor occur in the SW over sea ice off of Antarctica.

Including the clear-sky adjustment factors has a significant impact on comparisons of LW CREs between CERES and climate models. When zonal and regional mean LW CREs from CERES and a subset of CMIP6 climate models are compared, zonal mean differences between $60^{\circ} \mathrm{S}$ and $60^{\circ} \mathrm{N}$ and poleward of $65^{\circ} \mathrm{N}$ are noticeably smaller when the clear-sky adjustment is applied. Large improvements are obtained in regions where the adjustment factor is pronounced, such as over the west tropical Pacific, ITCZ, and SPCZ. In the SW, the clearsky adjustment has a much smaller impact overall. Thus the adjustments matter most for the most humid and cloudy tropical regions in the LW and regions around sea ice and with high aerosol loading in the SW.

The CERES team will be incorporating clear-sky adjustment factors to determine TOA and surface clear-sky fluxes and CREs starting with the EBAF Ed4.1 release in spring 2019. We expect that this will greatly benefit climate model evaluation efforts as well as studies that use observations to compute cloud feedback from climate system internal variations.

Acknowledgments. This research has been supported by the NASA CERES project. (The CERES EBAF Ed4.0 dataset was downloaded from https://cerestool.larc.nasa.gov/ord-tool/jsp/EBAF4Selection.jsp.) The NASA Langley Atmospheric Sciences Data Center processed the instantaneous Single Scanner Footprint (SSF) data used as input to EBAF Ed4.0. Surface observations of downward irradiances were collected from a number of sources. For land-based observations we include 19 sites from the Baseline Surface Radiation Network (BSRN; Driemel et al. 2018), available at www.bsrn.de. Eight surface sites come from NOAA's Global Monitoring Division (GMD) and SURFRAD network at NOAA's
Air Resources Laboratory/Surface Radiation Research Branch (Augustine et al. 2000) and are available from www.esrl.noaa.gov/gmd/grad. Nine surface sites come from the U.S. Department of Energy's Atmospheric Radiation Measurement (ARM) program and are available from www.arm.gov/data. Buoy observations come from two sources though separate projects. The Upper Ocean Processes group at Woods Hole Oceanographic Institution maintain the Stratus, North Tropical Atlantic Site (NTAS), and Hawaii Ocean Time Series (HOTS) buoys providing valuable time series of observations in climatically important regions of the ocean. Data are available at http://uop.whoi.edu/. We would also like to acknowledge the Tropical Atmosphere Ocean/Triangle Trans-Ocean Buoy Network (TAO/TRITON) Project Office of NOAA's Pacific Marine Environmental Labs (PMEL) where three groups of buoy data were downloaded: In the Pacific, the TAO/TRITON data, from the tropical Atlantic Ocean, the Prediction and Research Moored Array in the Tropical Atlantic (PIRATA), the Research Moored Array for African-Asian-Australian Monsoon Analysis and Prediction (RAMA) in the Indian Ocean, and the Kuroshio and PAPA buoy sites. All data are made available at www.pmel.noaa.gov/.

\section{REFERENCES}

Ackerman, T. P., and G. M. Stokes, 2003: The Atmospheric Radiation Measurement Program. Phys. Today, 56, https:// doi.org/10.1063/1.1554135.

Augustine, J. A., J. J. DeLuisi, and C. N. Long, 2000: SURFRAD-A national surface radiation budget network for atmospheric research. Bull. Amer. Meteor. Soc., 81, 2341-2358, https://doi.org/ 10.1175/1520-0477(2000)081<2341:SANSRB > 2.3.CO;2.

Barkstrom, B. R., 1984: The Earth Radiation Budget Experiment (ERBE). Bull. Amer. Meteor. Soc., 65, 1170-1185, https:// doi.org/10.1175/1520-0477(1984)065<1170:TERBE > 2.0.CO;2.

Bosilovich, M. G., and Coauthors, 2015: MERRA-2: Initial evaluation of the climate. Technical Report Series on Global Modeling and Data Assimilation, Vol. 43, NASA Tech. Rep. NASA/TM-2015-104606, 139 pp., https:/gmao.gsfc.nasa.gov/ pubs/docs/Bosilovich803.pdf.

Brodzik, M. J., and J. S. Stewart, 2016: Near-real-time SSM/ I-SSMIS EASE-grid daily global ice concentration and snow extent, version 5. NASA National Snow and Ice Data Center Distributed Active Archive Center, accessed 1 June 2018, https://doi.org/10.5067/3KB2JPLFPK3R.

Burrows, S. M., A. Dasgupta, S. Reehl, L. Bramer, P.-L. Ma, P. J. Rasch, and Y. Qian, 2018: Characterizing the relative importance assigned to physical variables by climate scientists when assessing atmospheric climate model fidelity. Adv. Atmos. Sci., 35, 1101-1113, https://doi.org/10.1007/s00376-018-7300-x.

Cess, R. D., and G. L. Potter, 1987: Exploratory studies of cloud radiative forcing with a general circulation model. Tellus, $\mathbf{3 9 A}$, 460-473, https://doi.org/10.1111/j.1600-0870.1987.tb00321.x.

, - - W. L. Gates, J.-J. Morcrette, and L. Corsetti, 1992: Comparison of general circulation models the Earth Radiation Budget Experiment data: Computation of clear-sky 
fluxes. J. Geophys. Res., 97, 20 421-20 426, https://doi.org/10.1029/ 92JD01726.

Clarke, A. D., and Coauthors, 2002: INDOEX aerosol: A comparison and summary of chemical, microphysical, and optical properties observed from land, ship, and aircraft. J. Geophys. Res., 107, 8033, https://doi.org/10.1029/2001JD000572.

Collins, W. D., P. J. Rasch, B. E. Eaton, B. V. Khattatov, J.-F. Lamarque, and C. S. Zender, 2001: Simulating aerosols using a chemical transport model with assimilation of satellite aerosol retrievals: Methodology for INDOEX. J. Geophys. Res., 106, 7313-7336, https://doi.org/10.1029/2000JD900507.

Dee, D. P., and Coauthors, 2011: The ERA-Interim reanalysis: Configuration and performance of the data assimilation system. Quart. J. Roy. Meteor. Soc., 137, 553-597, https://doi.org/ 10.1002/qj.828.

Donlon, C. J., M. Martin, J. Stark, J. Roberts-Jones, E. Fiedler, and W. Wimmer, 2012: The Operational Sea Surface Temperature and Sea Ice Analysis (OSTIA) system. Remote Sens. Environ., 116, 140-158, https://doi.org/10.1016/j.rse.2010.10.017.

Driemel, A., and Coauthors, 2018: Baseline Surface Radiation Network (BSRN): Structure and data description (19922017). Earth Syst. Sci. Data, 10, 1491-1501, https://doi.org/ 10.5194/essd-10-1491-2018.

Eyring, V., S. Bony, G. A. Meehl, C. A. Senior, B. Stevens, R. J. Stouffer, and K. E. Taylor, 2016: Overview of the Coupled Model Intercomparison Project Phase 6 (CMIP6) experimental design and organization. Geosci. Model Dev., 9, 19371958, https://doi.org/10.5194/gmd-9-1937-2016.

Gelaro, R., and Coauthors, 2017: The Modern-Era Retrospective Analysis for Research and Applications, version 2 (MERRA-2) J. Climate, 30, 5419-5454, https://doi.org/10.1175/JCLI-D-160758.1.

Gröbner, J., I. Reda, S. Wacker, S. Nyeki, K. Behrens, and J. Gorman, 2014: A new absolute reference for atmospheric longwave irradiance measurements with traceability to SI units. J. Geophys. Res., 119, 7083-7090, https://doi.org/10.1002/ 2014JD021630.

Hersbach, H., and Coauthors, 2018: Operational global reanalysis: Progress, future directions and synergies with NWP. European Centre for Medium-Range Weather Forecasts, ERA Rep. Series Doc. 27, 63 pp., https://www.ecmwf.int/file/276463/ download?token $=$ jSe39KV_.

Kato, S., F. G. Rose, D. R. Doelling, D. A. Rutan, T. E. Caldwell, L. Yu, and R. A. Weller, 2013: Surface irradiances consistent with CERES-derived top-of-atmosphere shortwave and longwave irradiances. J. Climate, 26, 2719-2740, https://doi.org/ 10.1175/JCLI-D-12-00436.1.

— , and Coauthors, 2018: Surface irradiances of Edition 4.0 Clouds and the Earth's Radiant Energy System (CERES) Energy Balanced and Filled (EBAF) data product. J. Climate, 31, 4501-4527, https://doi.org/10.1175/JCLI-D-17-0523.1.

Loeb, N. G., and Coauthors, 2018: Clouds and the Earth's Radiant Energy System (CERES) Energy Balanced and Filled (EBAF) top-of-atmosphere (TOA) Edition-4.0 data product. J. Climate, 31, 895-918, https://doi.org/10.1175/JCLI-D-17-0208.1.

Michalsky, J. J., E. Dutton, M. Rubes, D. Nelson, T. Stoffel, M. Wesley, M. Splitt, and J. DeLuisi, 1999: Optimal measurement of surface shortwave irradiance using current instrumentation. J. Atmos. Oceanic Technol., 16, 55-69, https://doi.org/10.1175/ 1520-0426(1999)016<0055:OMOSSI > 2.0.CO;2.

Minnis, P., and Coauthors, 2008: Cloud detection in nonpolar regions for CERES using TRMM VIRS and Terra and Aqua MODIS data. IEEE Trans. Geosci. Remote Sens., 46, 38573884, https://doi.org/10.1109/TGRS.2008.2001351.

Ohmura, A., and Coauthors, 1998: Baseline Surface Radiation Network (BSRN/WCRP): New precision radiometry for climate research. Bull. Amer. Meteor. Soc., 79, 2115-2136, https://doi.org/ 10.1175/1520-0477(1998)079<2115:BSRNBW>2.0.CO;2.

Potter, G. L., J. M. Slingo, J.-J. Morcrette, and L. Corsetti, 1992: A modeling perspective on cloud radiative forcing. J. Geophys. Res., 97, 20 507-20 518, https://doi.org/10.1029/92JD01909.

Ramanathan, V., 1987: The role of Earth radiation budget studies in climate and general circulation research. J. Geophys. Res., 92, 4075-4095, https://doi.org/10.1029/JD092iD04p04075.

— , R. D. Cess, E. F. Harrison, P. Minnis, B. R. Barkstrom, E. Ahmad, and D. Hartmann, 1989: Cloud-radiative forcing and climate: Results from the Earth Radiation Budget Experiment. Science, 243, 57-63, https://doi.org/10.1126/science. 243.4887.57.

Rienecker, M. M., and Coauthors, 2008: The GOES-5 Data Assimilation System-Documentation of versions 5.0.1, 5.1.0, and 5.2.0. NASA Tech. Rep. Series on Global Modeling and Data Assimilation NASA/TM-2008-104606, Vol. 27, 97 pp., https://ntrs.nasa.gov/archive/nasa/casi.ntrs.nasa. gov/20120011955.pdf.

Rutan, D. A., S. Kato, D. R. Doelling, F. G. Rose, L. T. Nguyen, T. E. Caldwell, and N. G. Loeb, 2015: CERES synoptic product: Methodology and validation of surface radiant flux. J. Atmos. Oceanic Technol., 32, 1121-1143, https://doi.org/ 10.1175/JTECH-D-14-00165.1.

Sohn, B.-J., J. Schmetz, R. Stuhlmann, and J.-Y. Lee, 2006: Dry bias in satellite-derived clear-sky water vapor and its contribution to longwave cloud radiative forcing. J. Climate, 19, 5570-5580, https://doi.org/10.1175/JCLI3948.1.

Trepte, Q. Z., and Coauthors, 2019: Global cloud detection for CERES Edition 4 using Terra and Aqua MODIS data. IEEE Trans. Geosci. Remote Sens., 57, 9410-9449, https://doi.org/ 10.1109/TGRS.2019.2926620.

Wielicki, B. A., B. R. Barkstrom, E. F. Harrison, R. B. Lee III, G. L. Smith, and J. E. Cooper, 1996: Clouds and the Earth's Radiant Energy System (CERES): An Earth observing system experiment. Bull. Amer. Meteor. Soc., 77, 853-868, https://doi.org/ 10.1175/1520-0477(1996)077<0853:CATERE > 2.0.CO;2.

Winker, D. M., and Coauthors, 2010: The CALIPSO Mission: A global 3D view of aerosols and clouds. Bull. Amer. Meteor. Soc., 91, 1211-1230, https://doi.org/10.1175/2010BAMS3009.1. 